\title{
Design of Wind Turbine Blade with Thick Airfoils and Flatback and its Aerodynamic Characteristic
}

\author{
Lijun $\mathrm{Xu}^{*}{ }^{, 1}$, Lei Xu${ }^{1}$, Lei Zhang ${ }^{2}$ and Ke Yang ${ }^{2}$ \\ ${ }^{I}$ Department of Electric and Information Engineering, Xinjiang Institute of Engineering, Urmqi, 830091, China \\ ${ }^{2}$ Institute of Engineering Thermophysics, Chinese Academy of Science, Beijing 100080, China
}

\begin{abstract}
After introducing the features of blade with thick airfoils and flatback, based on relevant parameters of Huaren $100 \mathrm{~kW}$ wind turbine, the paper designed blade with thick airfoils and flatback, introduced blade parameter design, and analyzed the aerodynamic performance of blades using GH bladed software, obtaining the relationship between power output of wind turbine with blade tip speed ratio $C_{p}$. Furthermore, it analyzed the aerodynamic performance of original design blades, modified blades and Huaren $100 \mathrm{~kW}$ blades, and assessed the aerodynamic performance of modified blade.
\end{abstract}

Keywords: Aerodynamic performance, parameter design, thick airfoils and flatback, wind turbine blade.

\section{INTRODUCTION}

Large-scaled blade has posed number of scientific and technical problems with the most prominent manifestations as following:

(1) The more complexity of three-dimensional separation and unsteady characteristics of flowing on the surface of large-scale blades bring more challenge to corresponding airfoil design $[1,2]$, the flow on blade surface and noise control.

(2) Large-scale blade has higher requirements on its structure, safety, and technologies to improve the structural strength of blades and reduce the quality of blades [3, 4];

(3) Due to increased flexibility of large-scaled blades, a completely new and high-efficient aeroelastic analysis has important significance on the appraisal of the load and fatigue properties of blades.

(4) To respond to the features of low density of wind energy in low wind speed, it needs to add the windchasing area of blades and meanwhile restricting the mass of blades and load increase;

(5) To improve the service capacity of the unit in typhoon area, it needs to develop anti-typhoon blades [5].

(6) To resolve contamination and icing and other conditions on the surface of blades, rough and lowsensitivity blades and anti-icing technologies also pose great challenge to designers [4].

The cost of large-scaled blades is extremely high, and new concepts and technologies in researches will cause great

*Address correspondence to this author at the Department of Electric and Information Engineering, Xinjiang Institute of Engineering, Urmqi, Xinjiang, 830091, China; Tel: (+86) 15214807296;

Fax: (+86) 09917977191; E-mail: xulijun612@163.com risk if they are directly used to make actual size blades. On the other hand, reduced-size wind tunnel can accommodate relatively small size, and many factors lead to the difficulty to maintain the similarity of geometry and fluidity between the models and prototypes. Therefore, to establish an experimental platform for small-scaled wind turbine set which can represent the features of large-scale wind-power blades will exert great importance on the design and $R \& D$ of large-scale wind turbine blade and on the development of basic development platform of large-scale wind turbine set.

\section{INTRODUCTION OF BLADES WITH THICK AIRFOILS}

Energy conversion efficiency of wind turbine is related to the lift force arising from air flowing over blades, consequently, blade aerofoils directly affect the energy conversion efficiency of wind turbine, and especially that high-performance rear aerofoil design has especially important significance on the design of large-diameter wind turbine. Due to the very low Renault number during the work of wind turbine blade, it needs to take full consideration and calculation of its running performance before design. Traditional fixed-pitch blades usually adopt the aerofoils of aerocrafts; however, with the development of wind power technology, some institutions have developed many kinds of special airfoils fro wind turbines to improve the energy conversion efficiency of wind turbine, and prolong the service life of blades, for example, NACA series aerofoils by National Advisory Committee for Aeronautics, FE-W series aerofoils by Swedish Aviation Institute, Denmark RIS $\phi$ aerofoil, $S \times \times \times$ aerofoil BY US NREL, and DU aerofoil by Netherlands Defg University.

The selection of aerofoils of modern large-scale wind turbine not only needs to meet the requirements of high $e$ ( $e=$ lift coefficient $C_{l} /$ resistance coefficients $C_{d}$ ), but also to 
guarantee the Reynolds number of every foliosine during the normal operation of wind turbine greater than the critical value $R_{e c r}$ ( $R_{e c r}$ of thin-airfoil blades is about $10^{4}$ and $R_{e c r}$ of thick-airfoil blades is about $10^{5} \sim 10^{6}$ ). The radius of modern large-scaled wind turbine rotor approximates one hundred meter with different pneumatic requirements for different parts along the shaft, therefore, all section parts of blades should adopt different aerofoils as required.

The development of blades with thick airfoils and flatback is the design concept proposed by the research group for adaptation to weak wind speed area and frequencyoccurring typhoon. Its main features lie in the capacity to reduce the load and weight of blades and to improve the structural strength of blades.

For the huge energy contained in weak wind speed area, it needs to increase the length of blades to improve energy capture. However, the increase of blade length leads to such problems as the increase in load and weight, which forces large-scaled wind-turbine blades to adopt low-load and high tip-speed ratio technologies [5]. The southeastern coastal areas of China usually suffer severe threats from typhoon, strong tropical cyclone above the sea in tropical and subtropical areas. Strong wind together with intense rotation effect, together leads to the multiple-folded turbulence intensity and turbulence energy, causing enormous destructive power to wind turbine blades, even to the whole turbine set [6-11]. When typhoon passes, the greatest change range of wind direction can reach 360 degree, thus blades in a state of shutdown had to bear enormous bending load for that they cannot be protected by the Pitch system.

Large-scaled wind turbine blade is a kind of component with beam shell structure with beam bearing main aerodynamic load and structure load, and shell mainly maintaining the aerodynamic shape of blades. This structure makes it possible to improve the absolute thickness and further increase the structural strength and stiffness of blades without increasing blade chord length. The specific measure is to adopt relatively thicker airfoil to replace thinner airfoil, thus comes the concept of "thick airfoil". Flatback is another form to improve the structural performance of blades utilizing the inside of blades which can increase blade strength without increasing blade weight. Compared with airfoils of sharp trailing edge with same thickness, airfoils of flatback has larger area, and accordingly, the feature of circumferential enhancement at the root of blades highlights the structural advantage of airfoils of flatback. Furthermore, flatback contributes to the improvement of aerodynamic performance at the root of blades, including increasing lift force and reducing rough sensitivity of leading edge.

To sum up, combining thick airfoils with flatback is superior over separately applying one measure improving the structural performance of blades.

\section{RUNNING PARAMETER DESIGN OF BLADES}

Parameter design of blades referred to relevant parameters of Huaren $100 \mathrm{~kW}$ wind turbine and adopted HARP opt, blade design code published by NERL. Thick airfoil CAS-W2-450 was adopt at the maximum chord length of blades, NACA18 airfoil was adopt for blade tip, and other airfoils all adopt DU series airfoil. The design used Focus to conduct preliminary load calculation, and was adjusted under the condition. After five plus design, the proposal was eventually determined. Finally, the aerodynamic load of blades will be subject to the results calculated by GH Bladed. As the debugging and first tested object, blades have no requirements for the maximum power coefficient and annual generating capacity.

The design conditions of blades include wind field type, unit basic parameters and restriction condition. Design standard and load calculation are subject to GL standard. Since the construction objective of blade testing platform is not to obtain the maximum annual generating capacity, but to the actual power coefficient curve of blades and the structural response performance of blades during actual operation, therefore, it needs no consideration the actual local wind condition, that is, wind field type $G L \Pi A$.

Blades adopt three-blade structure with the maximum blade root bending moment of $125.3 \mathrm{kN} \cdot \mathrm{m}$, variable propeller braking torque of $8.81 \mathrm{kN} \cdot \mathrm{m}$, the maximum pitch moment of $122 \mathrm{kN} \cdot \mathrm{m}$, single blade mass of $243 \mathrm{~kg}$, and the distance from the blade centroid to blade root of $2.63 \mathrm{~m}$. The distribution diameter of flange bolt at the root of blades is $350 \mathrm{~mm}$, with the bolt of $14 \times 20 \mathrm{~m}$, the length of screwed bolt of $100 \mathrm{~mm}$, the blot class of 10.9 and the maximum offset value restricted within $1.7 \mathrm{~m}$.

The pressure surface and suction surface of blades adopt symmetry layering with counterweight box is placed $5 \mathrm{~m}$ from the center of blades. The pressure surface and suction surface of blades have one cap respectively. The shear web is at the place of the central line of beam cap, between blade spanwise $1000 \mathrm{~mm}$ and $8000 \mathrm{~mm}$. Blades mainly use three kinds of glass fiber reinforced fabric and one kind of sandwich material with the following distribution at blades:

(1) Reinforced layers of beam cap and trailing edge adopt $1200 \mathrm{~g} / \mathrm{m}^{2}$ uniaxial cloth;

(2) Stressed skin, outer layers of webs, wet processing and other local reinforced layer are all $1000 \mathrm{~g} / \mathrm{m}^{2}$ biaxial cloth;

(3) Reinforced layers above (under) bolt sleeves of blade roots are $1200 \mathrm{~g} / \mathrm{m}^{2}$ tri-axial cloth;

(4) Core materials for sandwich structures adopt PVC foam.

\section{RUNNING PARAMETER DESIGN OF BLADES}

\subsection{Aerodynamic Shape of Blade}

Due to technology factors, the aerodynamic shape of blade was adjusted. It adds $200 \mathrm{~mm}$ blade tip the blade tip, with the width of blade tip of 0.045 . All control sections of blades thicken airfoils by $18 \%$, and the chord length of blade tip are obtained by elliptic equation as shown in Figs. (1-4) (out of confidentiality need, partial data applies dimensionless method. 


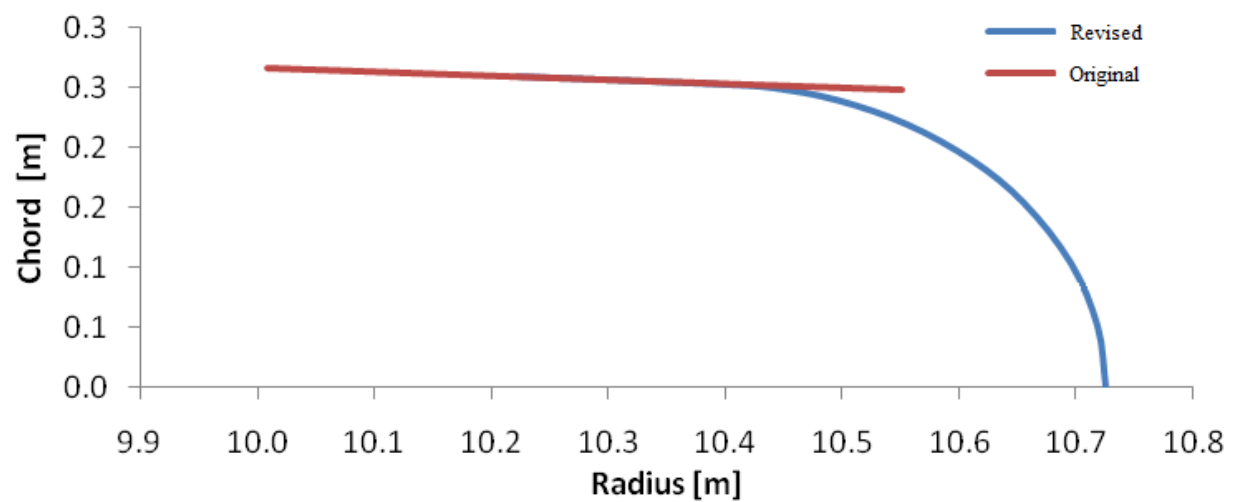

Fig. (1). Tip shape modification.

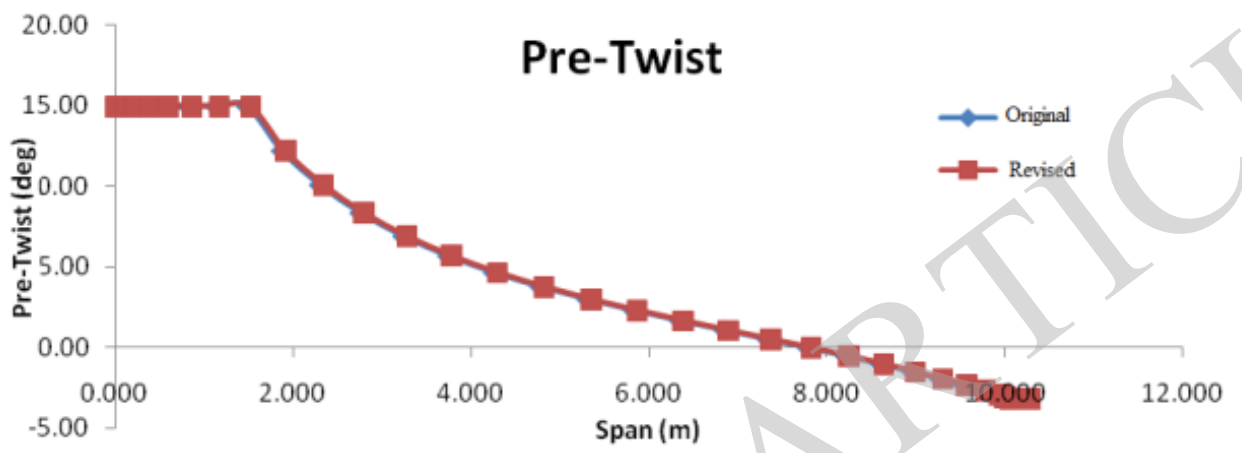

Fig. (2). Torsion angle of cross-modification.

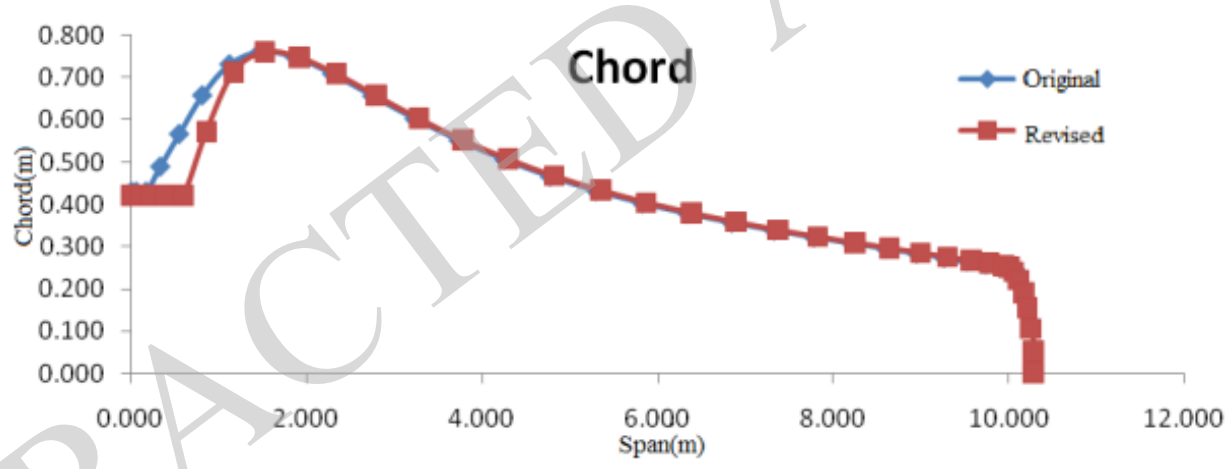

Fig. (3). Chord length variation of cross-modification.

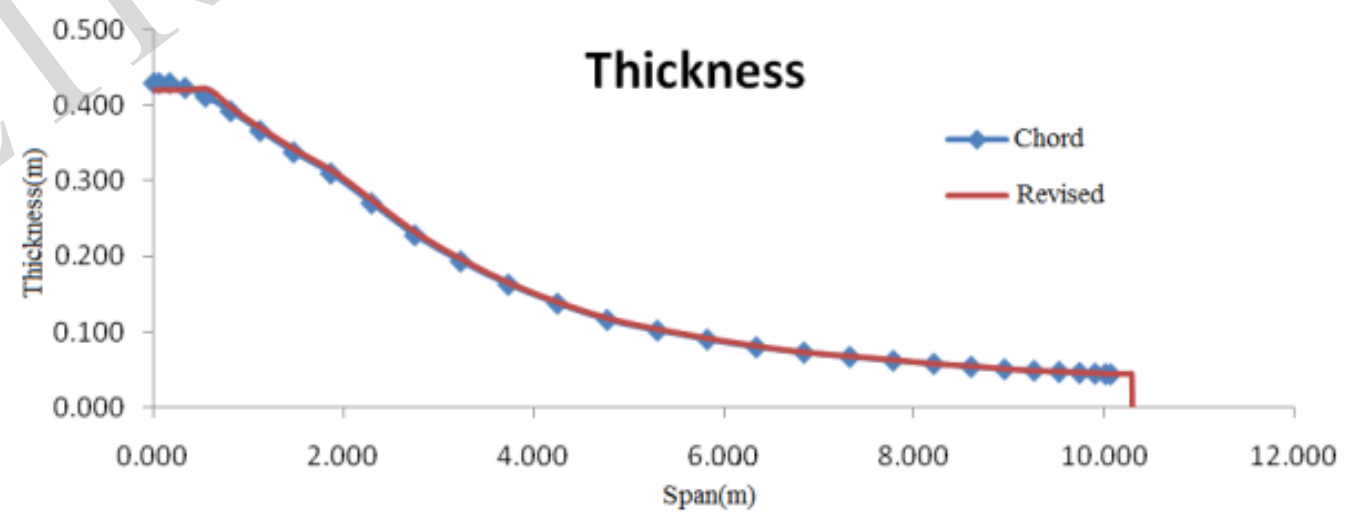

Fig. (4). The thickness variation of cross-modification. 


\subsection{Analysis of Blade Aerodynamic Performance}

\subsubsection{Aerodynamic Shape of Blade}

The optimal blade tip speed ratio(TSR)of original blades is 8.3, with the optinal $\mathrm{Cp}$ of 0.488. Blade wheels achieve $115.8 \mathrm{~kW}$ power under the working condition of $62 \mathrm{rpm}$ and $11.5 \mathrm{~m} / \mathrm{s}$. After adapting the blade, the $C_{p}-\lambda$ curve of blades can be obtained using WT_perf to assess the aerodynamic performance of blades as shown in Fig. (5).

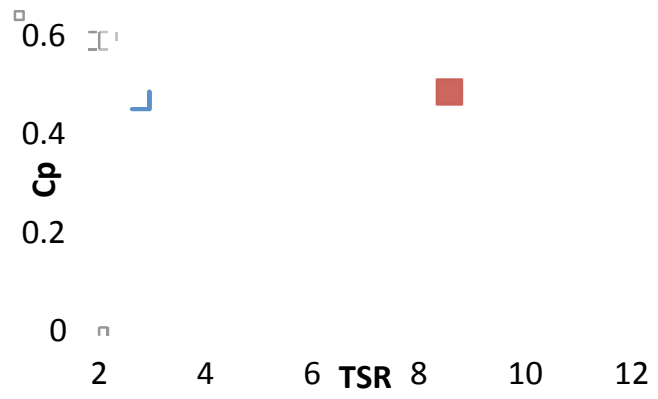

Fig. (5). $C_{p}-\lambda$ curve of blade.

Fig. (5) shows that the optimal blade tip speed ratio after adapting airfoil is 8.567 and the optimal $C_{p}$ is 0.4787 . When rotate speed is $62 \mathrm{r} / \mathrm{min}$ and pitch angle is $0^{\circ}$, the relationship between power output of wind turbines and tip speed ratio with $C_{p}$ is as shown in Table $\mathbf{1}$.
Table 1. The relationship of output power and TSR and $C_{p}$.

\begin{tabular}{|c|c|c|}
\hline Power $(k W)$ & TSR & $C_{p}$ \\
\hline 54.535 & 8.736638 & 0.4777 \\
\hline 76.822 & 7.765901 & 0.4726 \\
\hline 99.206 & 6.989311 & 0.4449 \\
\hline 115.771 & 6.353919 & 0.3901 \\
\hline 122.472 & 5.824426 & 0.3178 \\
\hline 124.676 & 5.376393 & 0.2545 \\
\hline 128.668 & 4.992365 & 0.2103 \\
\hline 134.047 & 4.65954 & 0.1781 \\
\hline 139.924 & 4.368319 & 0.1532 \\
\hline 145.425 & 4.111359 & 0.1327 \\
\hline 150.174 & 3.88295 & 0.1155 \\
\hline 153.884 & 3.678 & 0.1006 \\
\hline 156.498 & 3.494655 & 0.0877 \\
\hline 158.327 & 3.328243 & 0.0767 \\
\hline 159.328 & 3.176959 & 0.0671 \\
\hline 159.857 & 3.038831 & 0.0589 \\
\hline 160.292 & 2.912213 & 0.052 \\
\hline 160.775 & 2.795724 & 0.0461 \\
\hline
\end{tabular}

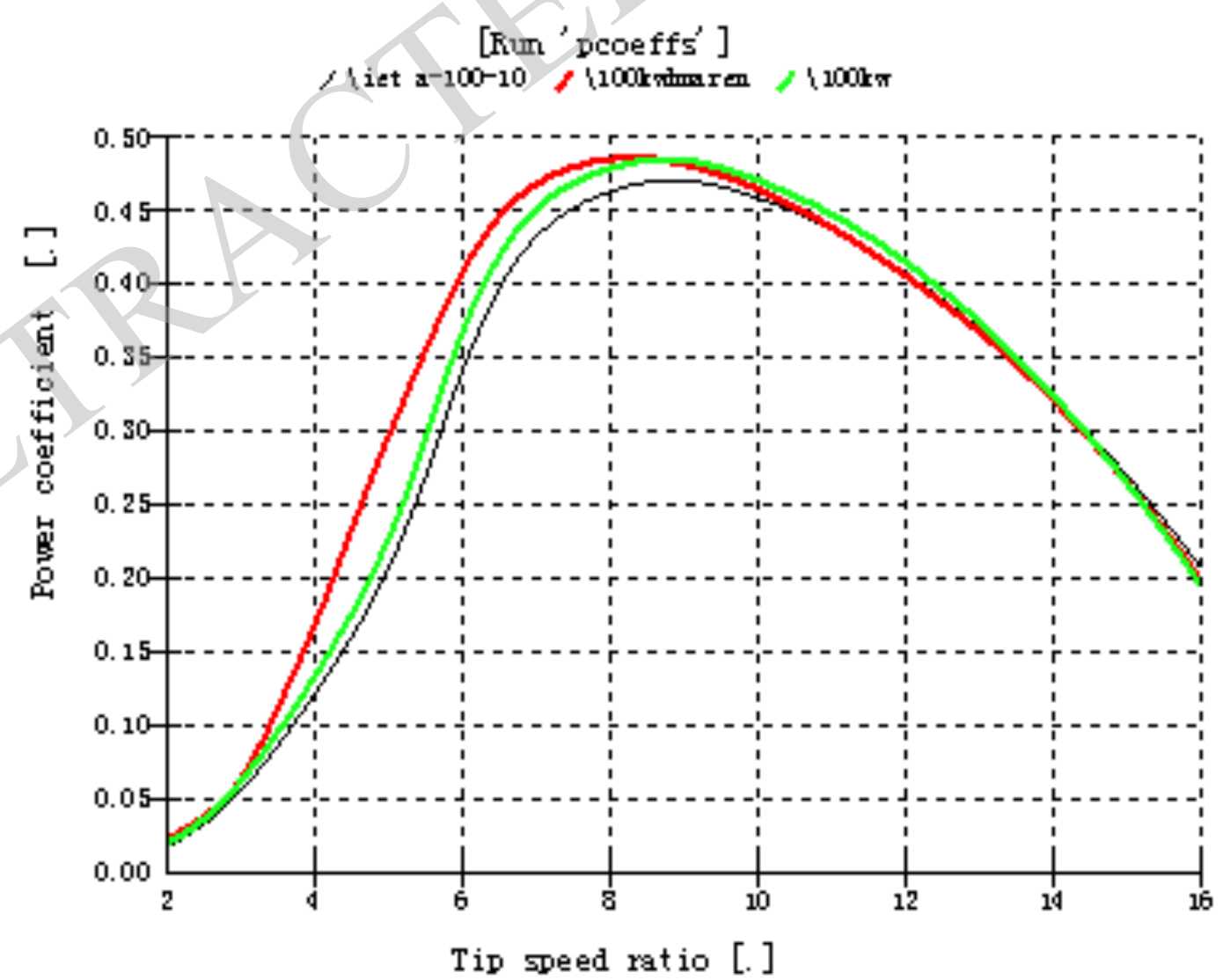

Fig. (6). Design comparison of blades. 


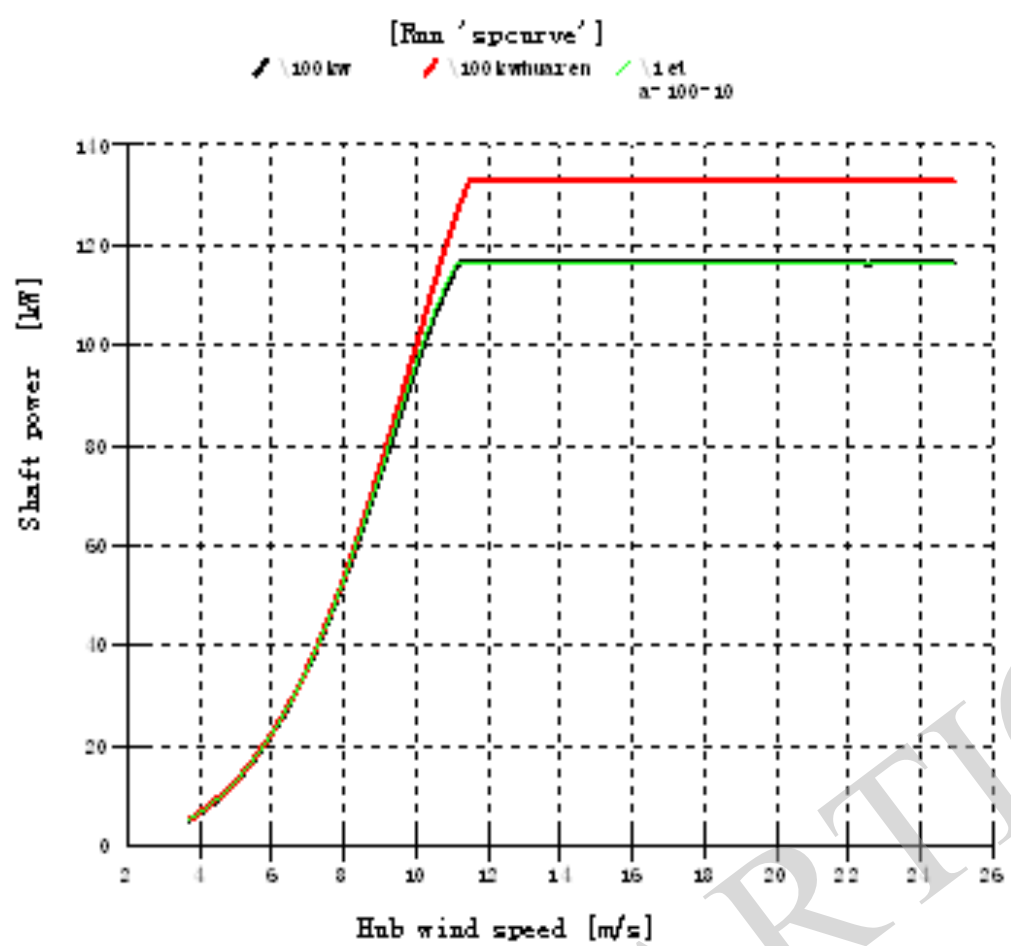

Fig. (7). Relationship of shaft power and hub wind speed.

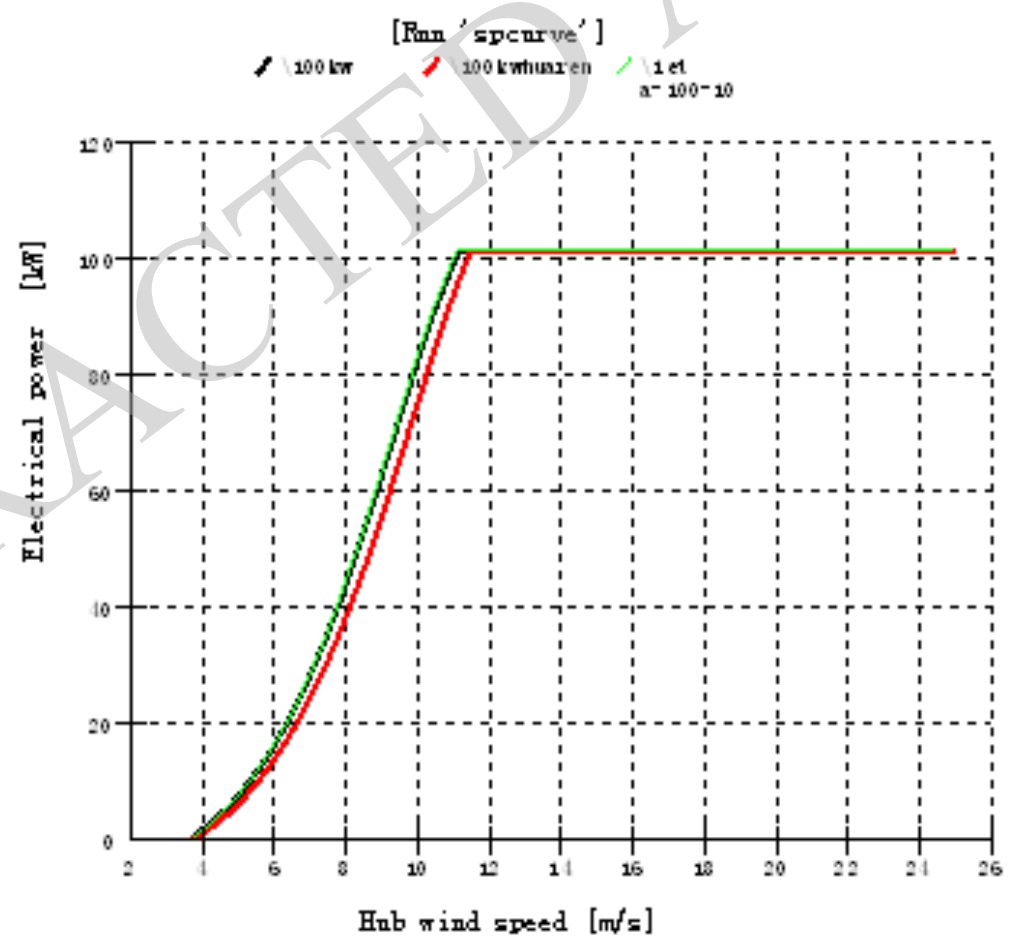

Fig. (8). Relationship of electrical power and hub wind speed.

In calculation, when rotation speed is $62 \mathrm{r} / \mathrm{min}$, and the wind speed is $11 \mathrm{~m} / \mathrm{s}$, the low speed shaft power of wind wheel is $115.771 \mathrm{~kW}$. After taking away machinery and power loss, it may obtain $100 \mathrm{~kW}$ generated power. Therefore, the rated wind speed of blades can be set as 11 $\mathrm{m} / \mathrm{s}, 0.5 \mathrm{~m} / \mathrm{s}$ higher than the design value.
Original design blades, improved blades and Huaren 100 $k W$ blades are conducted aerodynamic performance using Blade software, with the analysis results as shown in Figs. (6-8).

Figs. (6-8) revealed that improved blades may achieve rated output power with normal working ability and testing 
performance. On the other hand, the original blade has higher mechanical and electric motor losses, and its actual generated output is less than that of the improved blade although the low speed shaft power of the former is greater than that of the latter.

\section{CONCLUSION}

In general, the aerodynamic performance of the improved blade is inferior to that of the original blade; however, it has great potential for improvement in the following aspects:

(1) Improvement in optimization algorithm. Harp_opt optimizes the curve segments of steady state power; however, because the working condition of blade with small tip speed ratio accounts for low weight, optimization results will not seek in the direction of higher $C_{p}$;

(2) Limited by technological conditions, it needs to adjust geometrical shape, and separately optimize the twist and chord length of blades and other parameters;

(3) Airfoil selection. New blades select DU93-W-210 airfoil. However, it is hard to make high $C_{p}$ of small tip speed ratio using the airfoil, so it considers to use NACA21 airfoil for improved design.

\section{CONFLICT OF INTEREST}

The authors confirm that this article content has no conflict of interest.

\section{ACKNOWLEDGEMENTS}

This work is supported by the Xinjiang Natural Science Foundation (No. 2014211A021).

\section{REFERENCES}

[1] J.Martinez, B.Luca, and O. Probst, "An improved Bern model for the power curve prediction of Stall-Regulated wind turbines," Wind Energy, vol.8, pp.385-402, 2005.

[2] P.Migliore, and G.Bir, "A computerized method for preliminary structure design of composite wind turbine blades," In: Proceedings of the AIAA /ASEM Wind Energy SYM POSI, pp.26-37, 2001.

[3] J.Prieto, and G. Defrancisco, "Charaeterization of wind speed data acording to wind direction," Solar Energy, vol.66,pp.57-64,1999.

[4] D.X.Liu, R.J.Cao,"Experimental inverstigation on static structrual characteristics of a horizontal axis wind turbine," ACTA Energiae Solaris Sinica, vol.22, pp.436-439,2001.

[5] Z.P.Zhou, J.Y. Xiao, J.C.Zeng, "Structural analysis of large- scale composite wind turbine blade based on ANSYS," Journal of National University of Defense Technology, vol.32, pp.46-50, 2010.

[6] M.Lillico, and R.Butler,"Finite element and dynamic stiffness methods compared for modal analysis of composite wings," $A I A A$ Journal, vol.36, pp.2148-2151,2002.

[7] blade. Part A: Static test and equivalent single layered models", Composites Part a: Applied Sc-ience and M ANU Fact, Vol.41, pp.257-270,2010.

[8] Y. Zhiquan, M. Haomin, and D. Kang, "Experimental model analysis of the rotor blade of the horizontal axis wind turbine", Acta energiae solaris sinica,vol.22,pp.473-476, 2011.

[9] J. Lin, J. Zhuang, and B. Sun, , "Study on mechanical loading test of wind tubine", Machinery,vol. 51,pp.65-67,2013.

[10] T. Yang, W. Du, and Y.v, "Static load strain test of wind turbine blades", Research and exploration in laboratory, vol.30,pp.3339,2011 .

[11] P.A.Joosse, "Toward cost effective large turbine components with carbon fibers", Presented at the 2001 European Wind Energy Conf. Copenhagen, pp. 35-47. 